\title{
Stabilization of Silty Sand Soil Using Textile Material
}

\author{
Kiran S. P. ${ }^{1}$, Dr. A. N. Ramakrishna ${ }^{2}$ \\ ${ }^{1}$ Research scholar V.T.U-RRC Belgaum, Karnataka, India \\ ${ }^{2}$ Professor, Rajeev Institute of Technology Hassan, Karnataka, India
}

\begin{abstract}
The word sandy soil represents a soil which consists of more amount of sand particles and small amount of clay and silt particles. Sandy soil is generally found in western grads, coastal areas. The soil profile in coastal area often consists of sandy soil extended to a depth of 3 to $4 \mathrm{~m}$ from the ground level underlies by clay soil of medium consistency. The very low shearing resistance of foundation bed causes local as well as punching shear failure this type of soil profile found coastal area of Cochin in Kerala. sandy soil also consists of low plasticity, low bearing capacity and high moisture content, hence it is very essential to stabilize the sandy soil. Soil stabilization is one of most important for the construction which is widely used in connection with road pavement and foundation construction because it improves the engineering properties of soil such as strength, volume stability and durability. The use of hairsized polypropylene fibers in sandy soil stabilization applications has been popular in soil stabilization projects for its low cost compared with other stabilization agents. These materials have a high resistance towards chemical and biological degradation and do not cause leaching in the soil. The main objective of this study is to investigate the use of waste fiber materials in geotechnical applications and to evaluate the effects of polyester and polypropylene fibers on shear strength of unsaturated sandy soil. The results obtained are compared for the two samples and inferences are drawn towards the usability and effectiveness of fiber reinforcement as a stabilizer for deep foundation or raft foundation, road pavement as a cost effective approach. As the polyester and polypropylene fiber produce the tensile property it helps in the increase of strength of sandy soil. When polyester and polypropylene fiber which is a good reinforcement has well as binder used in different percentage with sandy soil as a stabilizer, the strength of the sandy soil has been evaluated by unconfined compressive testing and the result shows enormous increased in shear strength. For both polyester and polypropylene fiber it gives good result. But use of polypropylene fiber in percentage gives good shear strength compare to the polyester fiber.
\end{abstract}

Keywords: Unconfined Compressive Strength (UCS), Maximum Dry Density (MDD), Optimum Moisture Content (OMC)

\section{Introduction}

Soil is highly complex, heterogeneous and unpredictable material which has been subjected to vagaries of nature, without any control, The properties of a soil depend not only on its type but also on the conditions under which it exists and loading and drainage conditions[10,13].In order for the safe and strong structure, the soil around it plays a very critical role. So, to work with soils, we need to have proper knowledge about their properties and factors which affect their behavior. The process of soil stabilization helps to achieve the required strength in a soil needed for the construction work. From the beginning of construction work, the necessity of enhancing soil properties has come to the light. Ancient civilizations of the Chinese, Romans utilized various methods to improve soil strength some of these methods were so effective that their buildings and roads still exist. Improvement of certain desired properties of soil like compaction unconfined compression, shear strength, swelling characteristics can be undertaken by a variety of soil improvement techniques. There are many soil improvement techniques either chemical or mechanical. They may be classified as ground reinforcement, ground improvement, and ground treatment. All these techniques require skilled man-power and equipment to ensure adequate performance. Recently soil reinforcement is an effective and reliable technique for improving strength and stability of soils. The concept of earth reinforcement is an ancient technique and demonstrated abundant in nature by animals, birds and the action of tree roots. [14] The nature is the best example of earth reinforcement. In nature, the roots of plant and trees hold the earth during heavy rain and cyclone. These reinforcement resists tensile stress developed within the soil mass thereby restricting shear failure. Reinforcement interacts with the soil through friction and adhesion.

The inclusion of randomly distributed discrete fiber increases strength parameters of the soil same as in case of reinforced concrete construction.

In our present study, soil stabilization has been done with the help of randomly distributed of polypropylene and polyester fibers obtained from waste materials. The improvement in the shear strength parameters has been stressed upon and comparative studies have been carried out using different methods of shear resistance measurement. The important engineering applications of these materials is to serve as a backfill for mechanically stabilized walls and reinforced soil slopes. Foundations, road pavement For these engineering applications, the friction angle and the dilation angle of the sand are the most important engineering parameters. Fine sand induces greater porosity, water retention and resistance to penetration than coarse sand, they exhibit lower permeability. Porosity decreases when the heterogeneity of the sand grain distribution increases leading to an increase in resistance to penetration and decreases in permeability. The presence of silt particles leads to similar consequences. Thus silty sands are more compact than sandy soils, most silt particles occupying the voids between sand grains thereby reducing porosity and consequently permeability. The type clay and silt minerals present in sandy soil has great impact on availability of nutrients to the crops. The results of the study indicate that stabilization material polyester and polypropylene fiber can improve physical, chemical, and 


\section{International Journal of Science and Research (IJSR) \\ ISSN (Online): 2319-7064}

Index Copernicus Value (2013): 6.14 | Impact Factor (2014): 5.611

mechanic characteristics of sandy soil. Chemical bindings occur among the soil minerals and waste fiber. Plasticity and shear strength of soil increase in line with the increase of waste fiber concentration.

\section{Literature Survey}

E Bunga[1] The value of plasticity index of soil indicates the plasticity characteristic of the soil. Several literatures indicate the limit as follows: IP $=0$ (non-cohesive soil), IP $<7$ (low plasticity, partial cohesive soil), $7<\mathrm{IP}<17$ (moderate plasticity, cohesive soil) and IP $>17$ (high plasticity, cohesive soil). Soil mechanic characteristic is the ability/potential owned by soil to be able to hold pressures (internal and external) on it. One of the external pressures that can cause deformation at the soil surface is rain water. The shear failure or soil shearing is caused by relative movement between soil particles and not because the particles are broken. Therefore the strength of soil shearing depends on pressures between the soil particles.

William J. Orts i [3]The use of polyacrylamide as a soilstabilizing additive has expanded significantly in the past decade with particular focus in this report on (I) agricultural use to control soil erosion during irrigation .Polymer used for these applications range from 3 to 25 million, with the more common commercial products in the range of $12-20$ million.

Puppala[4] The use of hair-sized polypropylene fibers in soil stabilization applications has been popular in sandy soil stabilization projects for its low cost compared with other stabilization agents. These materials have a high resistance towards chemical and biological degradation and do not cause leaching in the soil have conducted a series of tests to study the engineering properties of clayey materials reinforced with randomly oriented fibers. The study used polypropylene fibers of nominal size of one inch and two inches in length. The physical and chemical properties of the fibers. These fibers have high resistance to chemical reaction and can be applied in high temperature conditions.

SCDT [6] Geotextiles, plastic covers, erosion control blankets, netting, and mats are rolled erosion control Geotextiles are a woven non-biodegradable polypropylene fabric. Woven geotextiles are used on disturbed soil areas where high strength materials are needed to endure abrasive forces through the life of a project. Geofiber can be used for drainage control and slope stabilization and roadway construction.

Shivanand Mali [7] Soft silty or clayey soils are extensively distributed worldwide and they can be improved with reinforcement in the form of randomly distributed fibers of natural and synthetic types. Among the natural fibers, coir and jute are produced in large quantities in South Asian countries. Polypropylene, polyester, polyethylene and glass fibers are widely available synthetic fibers. It is necessary to determine the optimum fiber content and fiber length for any fiber type in the laboratory prior to field applications. This paper reviews the strength behavior of cohesive soils reinforced with coir fibers, polypropylene fibers and scrap tire rubber fibers as reported from experimental investigation, that includes triaxial, direct shear and unconfined compression tests.

\section{Materials}

The Following materials are used in the study for the stabilization of sandy soil

\subsection{Sandy Soil}

Sandy soil sample were collected from udupi district Karnataka state, India the soil was taken from $1 \mathrm{~m}$ depth from the natural ground surface and soil is air dried and after oven dried at $110^{\circ} \mathrm{c}$ before testing

\subsection{Polypropylene Fibers}

Polypropylene fibers are new generation chemical fibers. [9]They are manufactured in large scale and have fourth largest volume in production after polyesters, polyamides and acrylics. About 4 million tonnes of polypropylene fibers are produced in the world in a year. $[8,12,13]$ Polypropylene is available in two forms, monofilament fibers and film fibers. The study evaluated the effect of the fiber reinforcement on the bearing capacity of the soil through UCS tests as described. The primary objective of this study was to evaluate the action of PP fibers at different volume fractions and fiber length to obtain a good physical and mechanical behavior of sandy soil. Fibers with length, $12 \mathrm{~mm}$ were employed for our present study. Fiber reinforcement significantly increases the UCS value increases for up to the certain percentage of fibers. The higher tensile strength along with the higher flexural strength is believed to be effective in reducing shrinkage in soil.

\subsection{Polyester fibers}

Polyester is a manufactured fiber in which the fiber-forming substance is any long-chain, [11,15] synthetic polymer composed of at least $85 \%$ of an ester of a substituted aromatic carboxylic acid. This can include, but is not restricted to, substituted terephtalic units, and parasubstituted hydroxy-benzoate units. Where in our present study polyester use as a good binder and also as good reinforcement due to his lack of softness it can give good frictional value with sandy type of soil.

Table 1: Properties Of Polypropylene, Polyester Fibers

\begin{tabular}{|c|c|c|}
\hline Behavior parameters & polypropylene & polyester \\
\hline Fiber type & Single fiber & Single fiber \\
\hline Unit weight $(\mathrm{g} / \mathrm{cm} 3)$ & 0.91 & 1.38 \\
\hline Diameter $(\mathrm{mm})$ & $0.034-0.05$ & $0.01-0.1$ \\
\hline Length $(\mathrm{mm})$ & $12-20$ & $2-30$ \\
\hline Breaking tensile strength $(\mathrm{Mpa})$ & 360 & 75 \\
\hline Modulus of elasticity (Mpa) & 3500 & 3100 \\
\hline Elongation In 50 (mm) & $500-10$ & $300-5$ \\
\hline Fusion point $\left({ }^{\circ} \mathrm{c}\right)$ & 165 & $150-200$ \\
\hline Burning point $\left({ }^{\circ} \mathrm{c}\right)$ & 590 & 258 \\
\hline Acid and alkali resistance & Very good & good \\
\hline Dispensability & excellent & good \\
\hline \multicolumn{2}{|c}{} \\
\end{tabular}




\section{International Journal of Science and Research (IJSR) \\ ISSN (Online): 2319-7064}

Index Copernicus Value (2013): 6.14 | Impact Factor (2014): 5.611

\section{Methodology}

Initially the engineering properties of natural sandy soil are determined. The optimum moisture content and maximum dry density of soil funded by mixing different percentage of polypropylene and polyester fibers for different soil samples, Then soil is effectively stabilized with fibers using that OMC and MDD. The amount of polypropylene fibers for stabilization is taken in the proportion of $0.1 \%, 0.2 \%, 0.3 \%$, $0.4 \%, 0.5 \%, 0.6 \%$ by dry weight of soil and the amount of polyester fibers was taken as same percentage for another sample by dry weight of soil. Using these proportions, mix samples were prepared as given below and a set of laboratory tests were performed to determine the UCS values of both natural soil and fiber-soil mixed samples.

1) Natural sandy soil.

2) Sandy Soil $+0.1 \%$ fibers

3) Sandy Soil $+0.2 \%$ fibers

4) Sandy Soil $+0.3 \%$ fibers

5) Sandy Soil $+0.4 \%$ fibers

6) Sandy Soil $+0.5 \%$ fibers

7) Sandy Soil $+0.6 \%$ fibers

\section{Experimentation:}

The basic experiments were conducted and the classification is carried out from engineering point of view to find out the suitability of soil as a subgrade for construction of pavement and soil below foundations.

\section{Specific gravity}

Specific gravity of a substance denotes the number of times that substance is heavier than water. In case of soils, Different types of soil have different specific gravities. The specific gravity of sandy soil used are mentioned below table.

\section{Grain Size Analysis}

Conducting sieve analysis test the soil is classified as: By AASHTO Classification Chart, it lies under the range of A-3 group, And by Unified soil classification system (USCS) and IS Classification system the soil is classified as SM (SandSilt Mixture).

\section{Atterberg Limit Test}

The Atterberg limits are a basic measure of the nature of fine grained soil. Depending upon the water content of the soil, it may appear in four states namely Soild, Semi Soild, Plastic, Liquid. In each state the consistency and behavior of the soil is different and it effects on engineering properties of soil. Thus, the boundary between each state can be defined based on a changes in the soil's behavior.

Table 2: Physical Prosperities Of The Sand Soil

\begin{tabular}{|c|c|}
\hline Specific gravity of solid, Gs & 2.48 \\
\hline \multicolumn{2}{|c|}{ Grain size distribution in \% } \\
\hline Clay $(<2 \mu \mathrm{m})$ & 9.8 \\
\hline Silt $(2 \mu \mathrm{m}-75 \mu \mathrm{m})$ & 22.7 \\
\hline Sand $(75 \mu \mathrm{m}-2 \mathrm{~mm})$ & 67.5 \\
\hline Atterberg Limit in \% \\
\hline Liquid limit & 36.7 \\
\hline Plastic limit & 19.3 \\
\hline Plastisity Index & 17.4 \\
\hline
\end{tabular}

\section{4. proctor compaction test}

To assess the amount of compaction and the water content required in the field, compaction tests are done on the soil samples in the laboratory. The tests provide the following results, the optimum moisture content and maximum dry density of normal sandy soil and also soil mixed with fibers in different percentage.

Table 3: Proctor compaction test of Polypropylene And Polyester Fibers mix with sand soil

\begin{tabular}{|c|c|c|c|c|}
\hline \multirow{2}{*}{ Percentage of fiber } & \multicolumn{2}{|c|}{ Polypropylene } & \multicolumn{2}{c|}{ Polyester } \\
\cline { 2 - 5 } & $\begin{array}{c}\mathrm{MDD} \\
\mathrm{kN} / \mathrm{m}^{3}\end{array}$ & $\begin{array}{c}\text { OMC } \\
\%\end{array}$ & $\begin{array}{c}\mathrm{MDD} \\
\mathrm{kN} / \mathrm{m}^{3}\end{array}$ & $\begin{array}{c}\text { OMC } \\
\%\end{array}$ \\
\hline Normal sandy soil & 17.50 & 18.50 & 17.50 & 18.50 \\
\hline sandy soil $+0.1 \%$ fibers & 17.35 & 19.40 & 17.46 & 19.95 \\
\hline sandy soil $+0.2 \%$ fibers & 17.04 & 20.20 & 17.20 & 20.88 \\
\hline sandy soil $+0.3 \%$ fibers & 16.88 & 21.10 & 16.95 & 21.70 \\
\hline sandy soil $+0.4 \%$ fibers & 16.75 & 22.24 & 16.85 & 22.85 \\
\hline sandy soil $+0.5 \%$ fibers & 16.48 & 22.85 & 16.65 & 23.78 \\
\hline sandy soil $+0.6 \%$ fibers & 16.13 & 23.25 & 16.43 & 25.40 \\
\hline
\end{tabular}

\section{Unconfined compressive test:}

The variation of unconfined compressive strength with addition of the different percentages of polypropylene and polyester fibers test shown in Table.4.

Table 4: Unconfined Compression Test of Polypropylene and Polyester Fibers mix with sand soil

\begin{tabular}{|l|l|l|}
\hline \multirow{2}{*}{ Percentage of fiber } & \multicolumn{2}{|l|}{ Unconfined Compression Test } \\
\cline { 2 - 3 } & $\begin{array}{l}\text { Polypropylene } \\
\mathrm{kN} / \mathrm{m}^{2}\end{array}$ & Polyester $\mathrm{kN} / \mathrm{m}^{2}$ \\
\hline Normal sandy soil & 89.5 & 89.5 \\
\hline sandy soil $+0.1 \%$ fibers & 93.8 & 91.15 \\
\hline sandy soil $+0.2 \%$ fibers & 99.5 & 94.15 \\
\hline sandy soil $+0.3 \%$ fibers & 107.5 & 100.9 \\
\hline sandy soil $+0.4 \%$ fibers & 118.7 & 102.5 \\
\hline sandy soil $+0.5 \%$ fibers & 104.7 & 101.3 \\
\hline sandy soil $+0.6 \%$ fibers & 102.6 & 100.8 \\
\hline
\end{tabular}

\section{Result and Discussion}

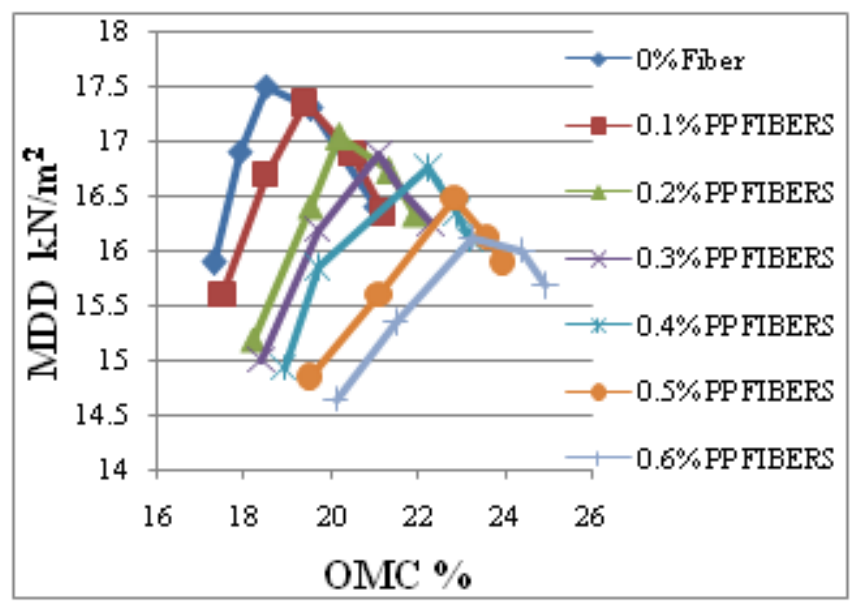

Figure 1: MDD and OMC For Different \% Of Polypropylene Fibers In Sandy Soil

Fig 1.It can be clearly indicated that by increasing in the parentage of polypropylene fibers in sandy soil the maximum dry density value decreases and the optimum moister content value increases, this is due to the fiber unit weight is very 


\section{International Journal of Science and Research (IJSR) \\ ISSN (Online): 2319-7064}

Index Copernicus Value (2013): 6.14 | Impact Factor (2014): 5.611

less comparatively and less then water and it replace the amount of soil while compaction and water taken for compaction is also more.

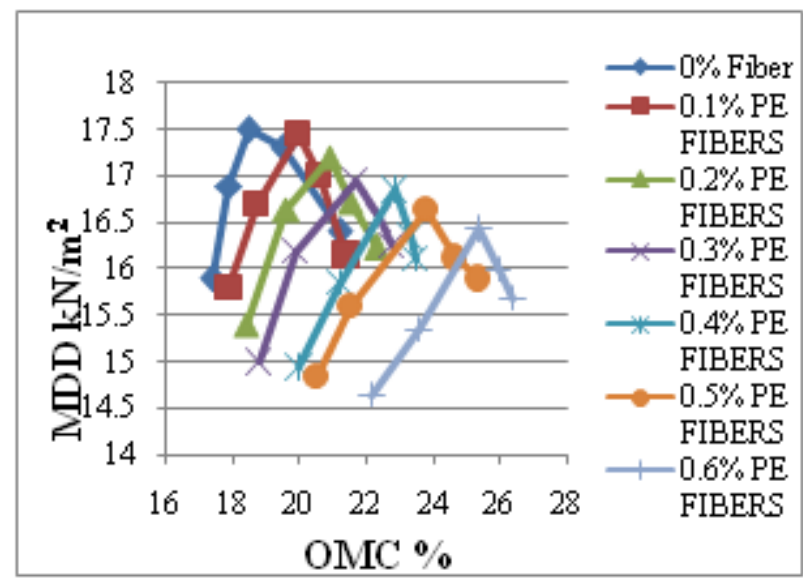

Figure 2: MDD And OMC For Different \%Of Polyester Fiber In Sandy Soil

Fig 2.In the case of polyester fiber mixed with sandy soil the density was slightly decreases not much as polypropylene mix because it having more unit weight and also comparatively it taken more water content for compaction because of its hydrophilicity nature.

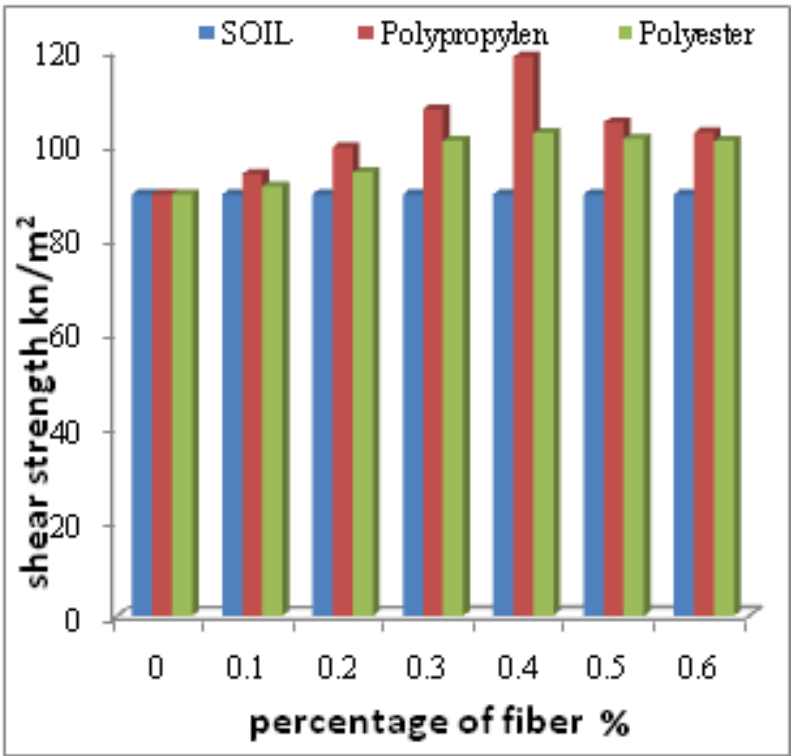

Figure 3: Comparison Of Maximum Shear Strength Of Polypropylene And Polyester Fibers

Fig 3. shows both normal soil, polypropylene and polyester fiber mixed sandy soil unconfined compression strength results it can be seen that By increasing the both fibers percentage the gradual increase in UCS value in both polypropylene, polyester fiber mixes. But in $0.4 \%$ of polypropylene fiber mix with sand soil shows very good UCS value compared with normal soil and polyester fiber mixed sandy soil

\section{Conclusion}

From the above experimental results it can be concluded that both the fibers are very good in improving the engineering property of the sandy soil as well as shear strength and also plasticity by increase of the percentages of the both type of fiber, Chemical binding occurs between minerals in the soil and chemical elements in both polypropylene polyester fibers. will result in increasing the angle of internal friction of sand and ductility of sandy soil. Where in case of polypropylene it can enhance up to $32 \%$ and polyester up to $17 \%$ of the strength compare with the normal soil mix. while comparing polypropylene and polyester fibers the polypropylene fiber shows good result in $0.4 \%$ mix with sandy soil and comparatively twice the strength value than polyester mix, Overall it can be concluded that fiber reinforced soil can be considered to be good ground improvement technique specially in engineering projects on weak soils where it can act as a substitute to deep/raft foundations, road pavement, reducing the cost as well as energy

\section{References}

[1] International journal of civil \& environmental engineering ijcee-ijens e bunga, hms pallu, m selintung "stabilization of sandy soil with asphalt"

[2] Amin Chegenizadeh1, Hamid Nikraz Curtin University, Australia"Laboratory Evaluation Of Fibre-Composite"

[3] William j. Orts i ; aicardo roa-espinosa robert e. Sojka "use of synthetic polymers and biopolymers for soil stabilization in agricultural construction, and military applications"k. Elissa, "title of paper if known," unpublished.

[4] Puppala and, Musenda 2000 "Fiber Reinforcement"

[5] Rohit maurya*, umesh kumar "utilization methods of polymer waste in geotechnical applications"

[6] State of California Department of Transportation"Guidance For Temporary Soil Stabilization"

[7] Shivanand Mali1 and Baleshwar Singh Former PG Student, Department of Civil Engineering"Strength Behaviour Of Cohesive Soils Reinforced With Fibers"

[8] Milind.v "Performance of Polypropylene Fibre Reinforced Concrete” DOI: 10.9790/1684-12112836 www.iosrjournals.org 30 | Page

[9] International Journal Of Emerging Technology And Advanced Engineering Website: Www.Ijetae.Com (Issn 2250-2459, Iso 9001:2008 Certified Journal, Volume 4, Special Issue 4, June 2014) International Conference On Advances In Civil Engineering And Chemistry Of Innovative Materials (Acecim'14)

[10] International Journal of Innovative Research in Science,Engineering and Technology(An ISO 3297: 2007 Certified Organization)Vol. 4, Issue 11, November 2015

[11] International journal of materials vol 2 may 2014"Mechanical properties of rice husks fiber reinforced polyester composites"

[12] Research and development services Washington Dc20591 "polypropylene fiber in portland cement concete pavement"

[13] Mousa f.Attom "Effect of polypropylene fiber on shear strength of sandy soil"

[14] kalpana maheshwari"effect of polyester fiber on strength properties of clayey soil of high plasticity"

[15] Salar bagherpour "fiber reinforced polyester composites" 